\title{
Molecular and chemical characterization by Fourier transform infrared spectroscopy of human breast cancer cells with estrogen receptor expressed and not expressed
}

\author{
Leila Büttner Mostaço-Guidolinn ${ }^{\text {a,* }}$, Luciana Sayuri Murakami ${ }^{a}$, Marina Ribeiro Batistuti ${ }^{\text {a }}$, \\ Auro Nomizo ${ }^{\mathrm{b}}$ and Luciano Bachmann ${ }^{\mathrm{a}}$ \\ ${ }^{\text {a }}$ Faculdade de Filosofia, Ciências e Letras de Ribeirão Preto (FFCLRP/USP), Departamento de Física \\ e Matemática, Ribeirão Preto, Brazil \\ ${ }^{\mathrm{b}}$ Faculdade de Ciências Farmacêuticas de Ribeirão Preto (FCFRP/USP), Departamento de Análises \\ Clínicas, Toxicológicas e Bromatológicas, Ribeirão Preto, Brazil
}

\begin{abstract}
The present study was designed to identify and compare the infrared absorption spectra of two human breast cancer cell lines: MCF-7 (estrogen receptor expressed, ER+) and SKBr3 (estrogen receptor non-expressed, ER-). Comparison between SKBr3 and MCF-7 cells revealed differences in the following absorption band areas: $1087 \mathrm{~cm}^{-1}$ (DNA), $1397 \mathrm{~cm}^{-1}$ $\left(\mathrm{CH}_{3}\right), 1543 \mathrm{~cm}^{-1}$ (amide II), $1651 \mathrm{~cm}^{-1}$ (amide I), $2924 \mathrm{~cm}^{-1}$ (fatty acids). Additionally, peak shifts were observed at $1122 \mathrm{~cm}^{-1}$ (RNA), $1397 \mathrm{~cm}^{-1}\left(\mathrm{CH}_{3}\right), 1651 \mathrm{~cm}^{-1}$ (amide I), $2851 \mathrm{~cm}^{-1}$ (fatty acids) and $2962 \mathrm{~cm}^{-1}$ (fatty acids). An analysis of the ratio between band areas was conducted, in order to obtain an index that could effectively distinguish between these two cell lines. The following ratios were found: $1650 \mathrm{~cm}^{-1} / 1540 \mathrm{~cm}^{-1}, 1650 \mathrm{~cm}^{-1} / 1740 \mathrm{~cm}^{-1}, 1650 \mathrm{~cm}^{-1} / 1084 \mathrm{~cm}^{-1}$ and $1120 \mathrm{~cm}^{-1} / 1084 \mathrm{~cm}^{-1}$. This work demonstrates that it is possible to distinguish between MCF-7 and SKBr3 cells through differences in their FTIR spectra. This work enables distinction between two cell lines from the same breast cancer.
\end{abstract}

Keywords: FTIR, SKBr3, MCF-7, cell, cancer, vibrational spectroscopy

\section{Introduction}

Breast cancer is the most frequently diagnosed cancer in women aged between 40 and 55, and it is heterogeneous in its clinical, genetic and biochemical profile. The large majority of the affected women present with a breast mass or mammographic abnormality as the only clinically detectable manifestation of the disease; yet, approximately 30 percent of the women diagnosed with breast cancer go on to develop metastatic disease that is ultimately fatal [1]. Distinct characteristics of the breast carcinoma can be exploited, in order to help determine the lifetime risk of disease development and the overall prognosis after diagnosis of breast carcinoma, as well as the chance of response to a specific therapy. In addition, increased understanding of breast carcinoma pathways may enhance our ability to design

\footnotetext{
${ }^{*}$ Corresponding author: Leila Büttner Mostaço-Guidolin, FFCLRP/USP DFM, Av Bandeirantes 3900, Ribeirão Preto, Brazil 14040-901. Tel.: +55 163602 0366/+55 16 36024441; Fax: +55 163602 4887; E-mail: leila.guidolin@ nrc.ca.
} 
targeted approaches for prevention or therapy. Thus, the biology of breast carcinoma can contribute vital information regarding many aspects of the disease.

Estrogens induce various physiological effects that allow the normal development and growth of female reproductive tissues, as well as regulation of bone integrity, cardiovascular function and central nervous system [19]. Aberrant expression of estrogen can induce pathophysiological effects that give rise to the growth of tumors, in particular those of the breast. Estrogen receptors are required for estrogenstimulated growth and proliferation of breast cancer. They are found to some degree in 50-80\% of breast tumors [2,6]. Endocrine treatments have been designed, to antagonize the effects of estrogen [1]. Approximately $70-80 \%$ of all breast tumors express the ER protein, and therefore they are termed ER positive $(\mathrm{ER}+)$. These tumors tend to grow more slowly, are better differentiated, and are associated with a slightly better overall prognosis [9]. Thus, ER expression is one of a few prognostic factors, along with auxiliary lymph node status, tumor size and histological grade [6,7,9]. In this context, the present study involved analysis of the Fourier transform infrared (FTIR) spectra of the breast cancer cell lines MCF-7 (ER+, or estrogen receptor positive) and SKBr3 (ER-, or estrogen receptor negative).

Vibrational spectroscopy has attracted a lot of attention in medicine because it can serve as an auxiliary method in the diagnosis of certain diseases, being a non-invasive technique [5,10,11,24]. This technique has several advantages, such as sensitivity, speed and the reagent-free nature of the measurement. FTIR spectroscopy can detect changes in the chemical composition and morphology of intact cells, including certain differences between different cell populations such as normal and tumor cells [11].

FTIR has several advantages, such as sensitivity, velocity and no requirement for staining or reagents. It is able to detect changes in the chemical composition of intact cells, making it useful for spotting differences in cell populations: for example, to tell the difference between normal and tumoral cells $[3,20,23,25]$. The absorption spectrum in the infrared spectral range provides information regarding the identification of the covalent bonds of a molecule mainly, but additional information about molecular conformation and intermolecular interactions can be extracted from the spectrum [12,17,27-29].

\section{Material and methods}

\subsection{Cellular cultures}

SKBr3 cells and MCF-7 cells are human breast cancer cell lines (ATCC, Manassas, VA, USA), and thus are presented in Fig. 1. These cells were grown at $37^{\circ} \mathrm{C}$ in a $5 \% \mathrm{CO}_{2}$ atmosphere, maintained in RPMI 1640 medium without phenol red (RPMI-S) supplemented with $7.5 \%$ fetal bovine serum (Gibco-Ivitrogen, BRL). Prior to the experiments, the cells had been washed and centrifuged (1000 rpm, $15 \mathrm{~min}$ ) in a solution of $0.9 \% \mathrm{NaCl}$, to remove all growth medium, according to procedures described by Mostaço-Guidolin et al. [15].

To guarantee that the influence of the number of cell behavior (film/agglomerates) would not affect the spectral difference, a normalization conducted by band area calculation was employed. The band area from one specific compound (in this case, $\mathrm{PO}_{2}$ ) was used to normalize all band areas obtained in all spectral data, and the effects related to the quantity of cells or cell agglomeration were minimized. In this work, we have cultured the samples of each cell line independently. This procedure was repeated five times for each cell line, respecting the same conditions af growth, drying procedures and spectral acquisition setups. 

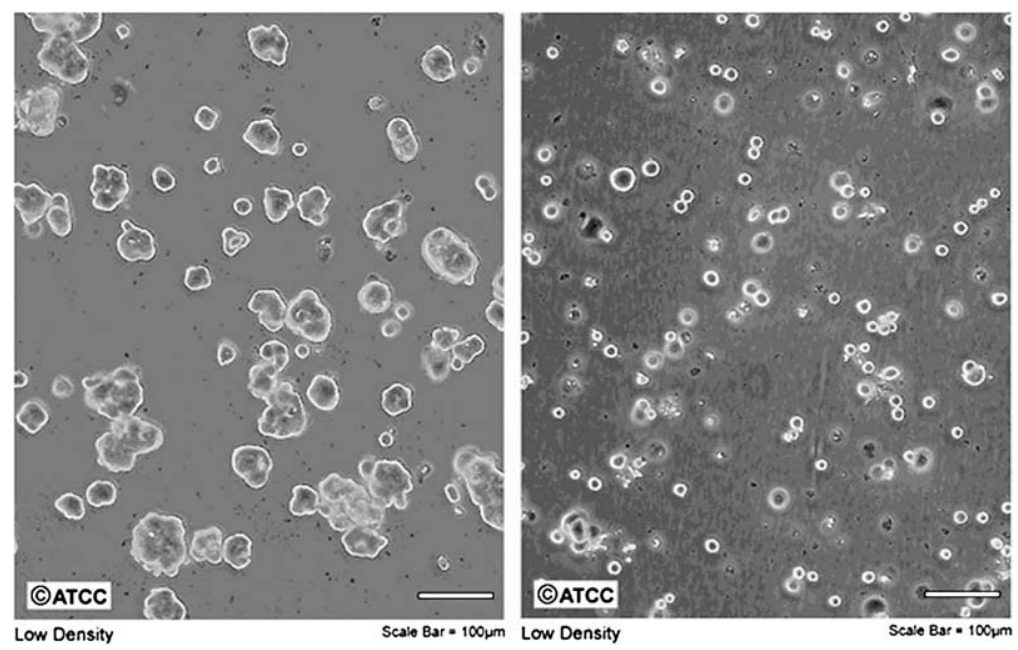

Fig. 1. Photos of MCF-7 cells (left) and SKBr3 cells (right) (ATCC, Manassas, VA, USA).

\subsection{Spectroscopic measurements}

The spectra were acquired on a Nicolet 380 spectrophotometer (Thermo Scientific Nicolet ${ }^{\mathrm{TM}}$, Waltham, MA, USA) at a $0.5 \mathrm{~cm}^{-1}$ resolution, 32 scans, in the $4000-900 \mathrm{~cm}^{-1}$ spectral range. For the FTIR measurements, cells were deposited on IR transparent $\mathrm{CaF}_{2}$ windows (approximately $10 \mu \mathrm{l}$ with $10^{7}$ $10^{8}$ cells). The samples were dried with $\mathrm{N}_{2}$ for about $10 \mathrm{~min}$. The fast drying procedure does not remove the entire water content from the sample but, we chose this methodology to preserve the biological characteristics of the cells. Another possibility would have been to lyophilize the entire sample, but this was not applied in this work because we were searching for fast procedures for cell identification and classification. For this reason it is important to remember during the discussion that the water content can introduce some errors to the band area measurement.

\subsection{Data analysis}

Before spectral analysis, the background signal was removed by using a straight line method from the Origin 8.0 software (OriginLab Corporation, MA, USA). The spectral data sets were analyzed in two ways: first, the spectral shifts in the absorption peaks were evaluated through analysis of the second derivatives of the absorbance spectrum. All the spectra were normalized to the band area positioned at $1240 \mathrm{~cm}^{-1}\left(\mathrm{PO}_{2}\right.$ asymmetric stretching). Following normalization, the average area of each band was calculated. A method of an algebraic sum of trapezoids was employed for area measurement. The differentiated values were calculated by averaging the slopes of two adjacent points for each data point. Both analyses, namely band area and peak displacement, were conducted by Student $t$-test statistics using $p<0.05$ as presented in Table 1 .

Ratios to discriminate between the two cell lines were selected from the references and from the observations of the present work. A list of ratios that better describe the differences between the two cell lines can be observed in Table 2. The ratio analysis has the objective to achieve biomarkers; i.e., a ratio between two bands that can differentiate between two cell lines. The significance of the ratio represents a relative proportion between a determined compound; e.g., in the first column of Table 2 there is the amide I/amide II ratio, the ratio $1650 \mathrm{~cm}^{-1} / 1540 \mathrm{~cm}^{-1}$ represents the relative composition of amide I to 
Table 1

FTIR bands obtained for the SKBr3 and MCF-7 (negative and positive estrogen-receptor breast cancer cells, respectively) cell lines

\begin{tabular}{|c|c|c|c|c|}
\hline \multicolumn{2}{|c|}{ SKBr3 } & \multicolumn{2}{|c|}{ MCF-7 } & \multirow[t]{2}{*}{ Chemical assignmen } \\
\hline Band area (a.u.) & Peak position $\left(\mathrm{cm}^{-1}\right)$ & Band area (a.u.) & Peak position $\left(\mathrm{cm}^{-1}\right)$ & \\
\hline $\mathbf{0 . 3 5} \pm \mathbf{0 . 1 2}$ & $1039.80 \pm 0.40$ & $\mathbf{0 . 1 1} \pm \mathbf{0 . 0 1}$ & $1042.60 \pm 0.10$ & $\nu \mathrm{C}-\mathrm{O}$ \\
\hline $0.17 \pm 0.04$ & $1087.20 \pm 0.18$ & $0.29 \pm 0.08$ & $1084.80 \pm 0.05$ & $\nu \mathrm{PO}_{2}$ sym. \\
\hline $0.08 \pm 0.02$ & $1122.00 \pm 0.40$ & $0.10 \pm 0.02$ & $1120.80 \pm 0.04$ & $\nu \mathrm{C}-\mathrm{N}$ and $\nu \mathrm{C}-\mathrm{C}$ \\
\hline 1.00 & $1232.30 \pm 0.14$ & 1.00 & $1230.20 \pm 0.12$ & $\nu \mathrm{PO}_{2}$ asym. \\
\hline $0.18 \pm 0.01$ & $1309.70 \pm 0.12$ & $0.13 \pm 0.01$ & $1310.60 \pm 0.05$ & amide III \\
\hline $\mathbf{1 . 0 2} \pm \mathbf{0 . 1 7}$ & $\mathbf{1 3 9 7 . 7 0} \pm \mathbf{0 . 0 7}$ & $1.36 \pm \mathbf{0 . 1 6}$ & $1401.40 \pm 0.13$ & $\varsigma \delta \mathrm{CH}_{3}$ sym. \\
\hline $0.50 \pm 0.02$ & $1454.50 \pm 0.16$ & $0.30 \pm 0.03$ & $1454.80 \pm 0.05$ & $\varsigma \delta \mathrm{CH}_{3}$ asym. \\
\hline $2.21 \pm 0.28$ & $1543.30 \pm 0.11$ & $4.15 \pm 0.55$ & $1542.60 \pm 0.10$ & $\nu \mathrm{N}-\mathrm{H}$ and $\nu \mathrm{C}-\mathrm{N}$ \\
\hline $10.99 \pm 0.86$ & $1641.30 \pm 0.18$ & $14.13 \pm 0.85$ & $1643.80 \pm 0.98$ & $\nu \mathrm{C}=\mathrm{O}$ \\
\hline $1.22 \pm 0.28$ & $1651.80 \pm 0.83$ & $3.25 \pm 0.55$ & $1650.00 \pm 0.63$ & $\nu \mathrm{C}=\mathrm{O}$ \\
\hline $0.18 \pm 0.06$ & $1740.70 \pm 0.03$ & $0.14 \pm 0.04$ & $1742.20 \pm 0.10$ & $\nu \mathrm{C}=\mathrm{O}$ \\
\hline $0.37 \pm 0.05$ & $2851.80 \pm 0.09$ & $0.24 \pm 0.07$ & $2854.00 \pm 0.09$ & $\nu \mathrm{CH}_{2}$ sym. \\
\hline $\mathbf{0 . 5 9} \pm \mathbf{0 . 1 0}$ & $2924.30 \pm 0.17$ & $\mathbf{0 . 3 4} \pm \mathbf{0 . 0 2}$ & $2923.20 \pm 0.04$ & $\nu \mathrm{CH}_{2}$ asym. \\
\hline $0.44 \pm 0.25$ & $2962.30 \pm 0.06$ & $0.14 \pm 0.02$ & $2964.60 \pm 0.07$ & $\nu \mathrm{CH}_{3}$ asym. \\
\hline $0.43 \pm 0.14$ & $3072.30 \pm 0.40$ & $0.44 \pm 0.08$ & $3047.60 \pm 0.73$ & $\nu \mathrm{CH}_{3}$ sym. \\
\hline
\end{tabular}

Notes: The assignment was based on different works in the literature $[13,15,16]$. The symbols concerning the chemical assignment are related to the stretching vibrational mode $(\nu)$, scissoring $(\delta)$, bending $(\varsigma)$, and symmetrical (sym.) and asymmetrical (asym.) modes. Band area and peak positions in bold are the values which presented significant differences, considering $p<0.05$.

amide II in the sample. To differentiate between the two cell lines it is not necessary to have the means of the final ratio, because this is a mathematical index that will help tumor diagnosis.

\section{Results}

Figure 2 provides a complete view of the spectral region between 3800 and $1100 \mathrm{~cm}^{-1}$. Figures 3 and 4 represent a detailed view of the spectra and the second derivative from both cell lines studied in this work.

Figure 3 represents a detailed view of the spectra and the second derivative from both cell lines studied in this work, and it is related to the region between 1800 and $1100 \mathrm{~cm}^{-1}$. According to Fig. 3 the spectra of the MCF-7 and SKBr3 cell lines are dominated by two bands, assigned to the absorption modes of proteins. The most intense is the amide I band, centered near $1640 \mathrm{~cm}^{-1}$, which corresponds to the $\mathrm{C}-\mathrm{O}$ stretching coupled with the $\mathrm{N}-\mathrm{H}$ bending and the $\mathrm{C}-\mathrm{N}$ stretching modes of peptide linkages. The second band, centered at $1540 \mathrm{~cm}^{-1}$, corresponds to amide II - predominantly a C-N stretching mode $[13,15,16]$.

In Fig. 4 it is possible to observe in detail the $\mathrm{C}-\mathrm{H}$ absorption bands, presenting the region located between 3200 and $2700 \mathrm{~cm}^{-1}$; the position and area values for both cell lines can be visualized in Table 1 .

The absorption spectra of both cell lines evaluated here contain absorption bands similar to those of other cell lines previously studied by Mostaço-Guidolin et al. [15]. Table 1 presents the absorption bands identified for each cell line; the band areas and peak positions which presented significant statistical differences $(p<0.05)$ are in bold. In the region of $1000-1300 \mathrm{~cm}^{-1}$, the main spectral features are the 


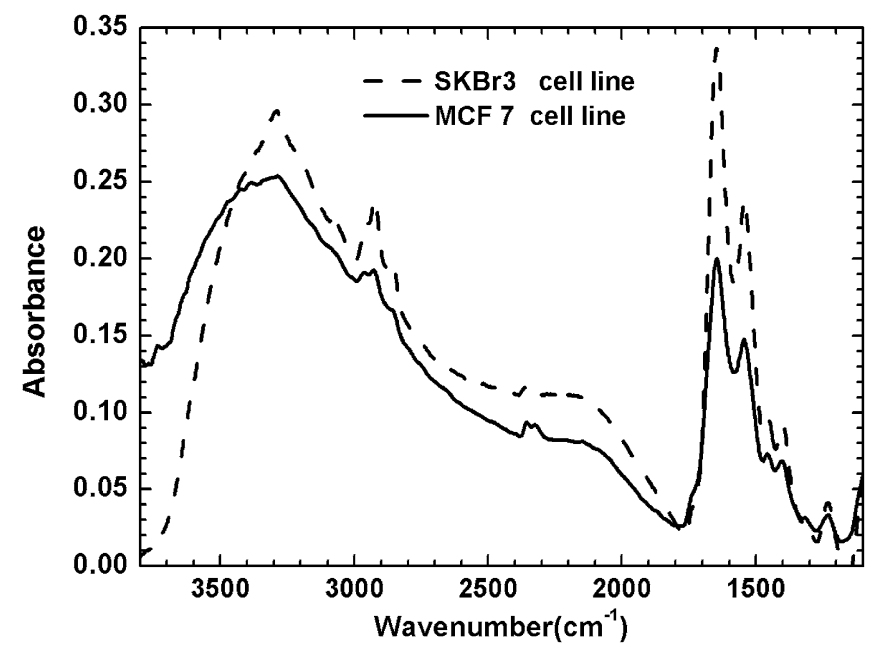

Fig. 2. Absorption infrared spectra of the SKBr3 cell (non-estrogen receptors expressed) and the MCF-7 cell (estrogen receptor expressed) in the entire spectral range $4000-1000 \mathrm{~cm}^{-1}$. The spectra is composed of two intense absorbance regions which will better exposed in the following figures.

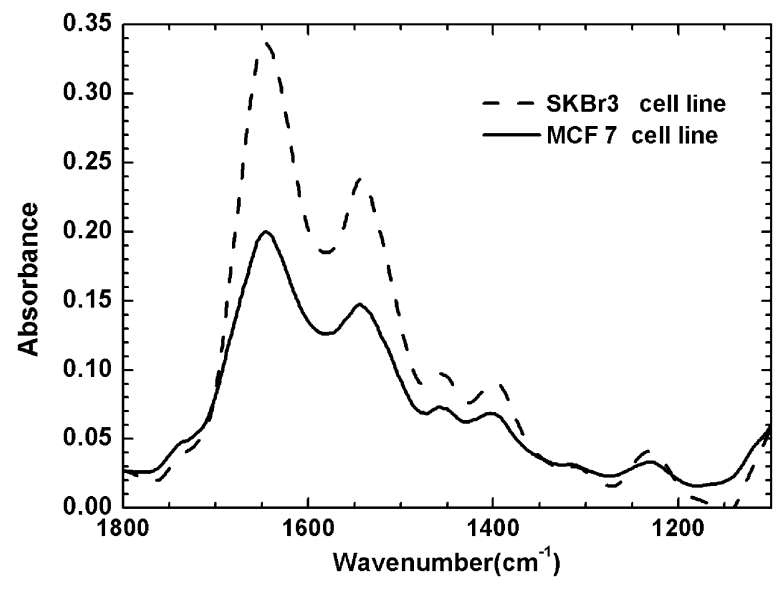

(A)

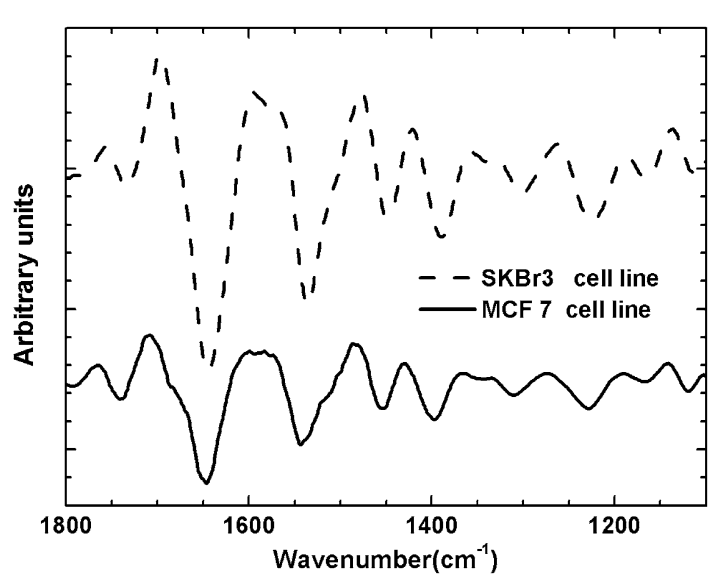

(B)

Fig. 3. (A) Infrared absorption spectra of the SKBr3 cell and the MCF-7 cell in the $1800-1100 \mathrm{~cm}^{-1}$ spectral range, and (B) the second derivative for the same cell lines and spectral range.

vibrations of the nucleic acid $\mathrm{PO}_{2}$ stretching mode and the $\mathrm{C}-\mathrm{O}$ stretching vibrations from the glycogen carbohydrate residues in the glycogen. Other bands related to nucleic acids, originated by $\mathrm{C}-\mathrm{O}$ polysaccharides stretching $\left(1039 \mathrm{~cm}^{-1}\right), \mathrm{C}-\mathrm{OH}$ stretching $\left(1087 \mathrm{~cm}^{-1}\right)$ from DNA sugar and other compounds, and $\mathrm{C}-\mathrm{N}$ and $\mathrm{C}-\mathrm{C}$ stretching $\left(1122 \mathrm{~cm}^{-1}\right)$ were also detected $[13,16]$.

The band located at $1239 \mathrm{~cm}^{-1}$ is assigned to the asymmetric $\mathrm{PO}_{2}$ stretching from phosphodiester bonds $[13,16]$. This band was used as the basis for spectral normalization, compensating for any effects from the difference in the number of cells in the films deposited on the $\mathrm{CaF}_{2}$ windows [15]. This band was chosen because the phosphate moiety is found only within phosphodiester connections and phospholipids (in the membrane), and its intensity is generally unaffected by changes in the environment (washing, dry film creation, etc.). The amide I band is often used for normalization, but this absorption 


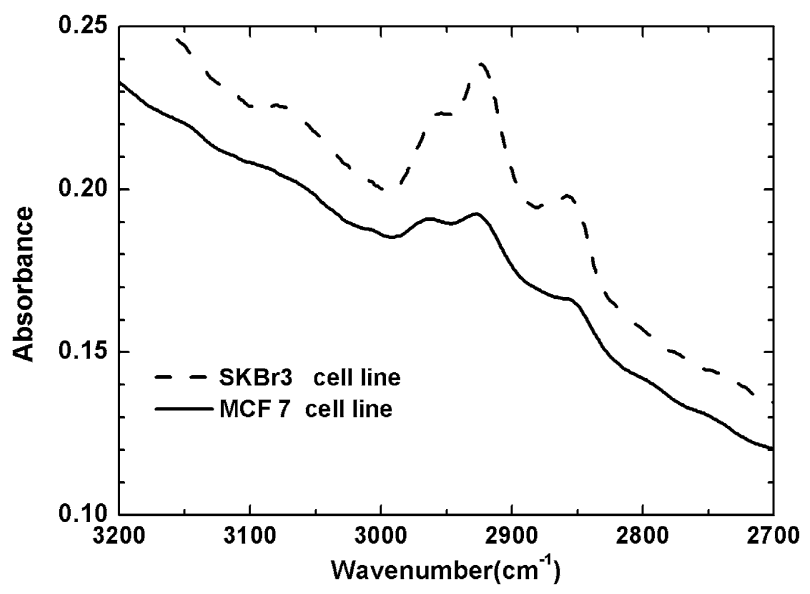

(A)

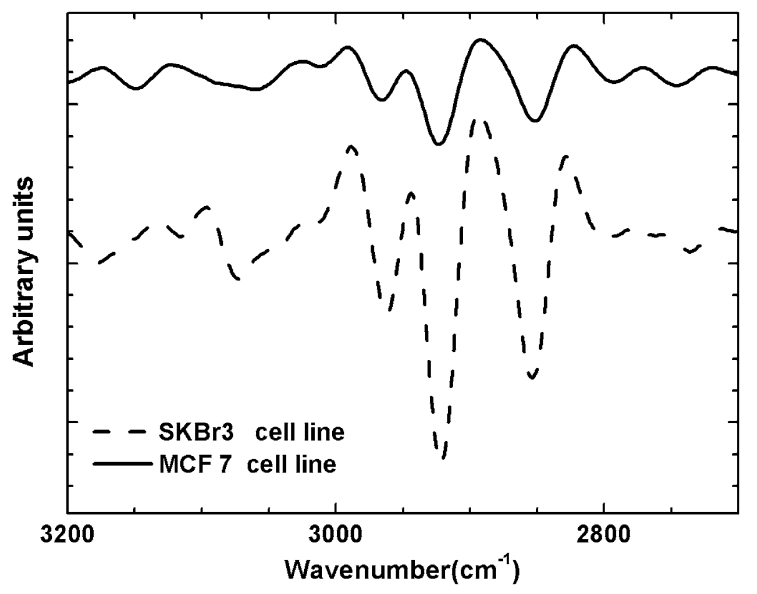

(B)

Fig. 4. (A) Infrared absorption spectra of the SKBr3 cell and the MCF-7 cell in the $3200-2700 \mathrm{~cm}^{-1}$ spectral range. (B) The second derivative spectra for the same cell lines and spectral region.

Table 2

Absorption band ratios selected for differentiation between the SKBr3 and MCF-7 cells line

\begin{tabular}{|c|c|c|c|c|c|c|c|c|c|}
\hline \multirow[b]{3}{*}{ Whynumbr(mom -1 ) } & \multicolumn{9}{|c|}{ Biochemical assignment ratio } \\
\hline & $\frac{\text { Amide I }}{\text { AmideII }}$ & $\frac{\mathrm{RNA}}{\mathrm{DNA}}$ & $\frac{\text { Amide I }}{\text { DNA }}$ & $\frac{\text { Amide I }}{\text { Lipids }}$ & $\frac{\text { Protein }}{\text { RNA }}$ & $\frac{\text { Protein }}{\text { Lipids }}$ & $\frac{\text { Protein }}{\text { Lipids }}$ & $\frac{\text { Protein }}{\text { RNA }}$ & $\frac{\text { Lipids }}{\text { RNA }}$ \\
\hline & $\frac{1650}{1540}$ & $\frac{1120}{1085}$ & $\frac{1650}{1085}$ & $\frac{1650}{1740}$ & $\frac{1651}{1120}$ & $\frac{1651}{2851}$ & $\frac{1651}{2962}$ & $\frac{2851}{1120}$ & $\frac{2962}{1120}$ \\
\hline
\end{tabular}

Notes: These ratios were selected according to the literature and evidences from this work. The first and second lines correspond to the biochemical ratio, and the two following lines correspond to the wavenumber used for ratio calculation.

profile is very sensitive to conformation and hydrogen-bonding. Since we observed significant shifts in the amide I absorption maximum, as well as additional changes that indicate modifications in the proportion of secondary structures, we believe that the amide I band is not the best possible reference for normalizations.

Through the second derivative spectra of the SKBr3 and MCF-7 cells, it was possible to verify the presence of peak shifts, related to the bands located at $1122 \mathrm{~cm}^{-1}$ (RNA), $1397 \mathrm{~cm}^{-1}\left(\mathrm{CH}_{3}\right.$ from proteins and lipids), $1651 \mathrm{~cm}^{-1}$ (amide I- $\beta$ sheet), $2851 \mathrm{~cm}^{-1}$ (fatty acids) and $2962 \mathrm{~cm}^{-1}$ (stretching of fatty acids). There were significant differences in the absorption band areas of the bands located in the regions of $1087 \mathrm{~cm}^{-1}$ (C-OH stretching), $1397 \mathrm{~cm}^{-1}\left(\mathrm{CH}_{3}\right.$ from proteins and lipids), $1543 \mathrm{~cm}^{-1}$ (amide II stretching), $1651 \mathrm{~cm}^{-1}$ (amide I- $\beta$ sheet) and $2924 \mathrm{~cm}^{-1}$ (stretching of fatty acids), as shown in Table 2.

In this study two human breast cancer cell lines were analyzed, namely MCF-7 (estrogen receptor expressed, $\mathrm{ER}+$ ) and $\mathrm{SKBr} 3$ (estrogen receptor non-expressed, ER-). Estrogen receptor (ER) is a member of the nuclear hormone family of intracellular receptors that is activated by the hormone $17 \beta$-estradiol (estrogen). It binds directly to estrogen response elements (EREs), to regulate gene transcription, according to Peng et al. [18]. However, the estrogen receptor also has additional functions independent of DNA binding.

Pollock et al. [19] suggest that two mechanisms contribute to explaining the causes of tumorigenesis. Firstly, the binding of estrogen to the ER stimulates proliferation of mammary cells, thereby increasing 
cell division and DNA replication. Secondly, cells that present expressed estrogen are able to synthesize certain biomolecules, causing a rise in the number of genes and proteins. In our study, different band areas were found in the region related to proteins and DNA, specifically at $1085 \mathrm{~cm}^{-1}$ (DNA), $1542 \mathrm{~cm}^{-1}$ (amide II) and $1650 \mathrm{~cm}^{-1}$ (amide I), where the MCF-7 cell line (ER+) displays a larger absorbance intensity compared with the SKBr3 cell line (ER-). Specifically, the protein and DNA band areas in the spectrum of the MCF-7 cell line (ER+) have a value almost twice the value obtained for the SKBr3 cell line $(\mathrm{ER}-)$.

A closer look at the lipids region between 2800 and $3000 \mathrm{~cm}^{-1}$, as shown in Fig. 4, revealed differences with relation to band area $\left(2924\right.$ and $\left.2962 \mathrm{~cm}^{-1}\right)$ and peak displacement $\left(2962 \mathrm{~cm}^{-1}\right)$. Phosphatidylcholines are a class of phospholipids which incorporate choline as a head group. They are a major component of biological membranes and are called "essential phospholipids" [14]. Rohlfs et al. [22] and Rillema et al. [21] suggest the choline is supplied by the diet and considered an essential nutrient in mammals, and mammary epithelial cells accumulate choline from the plasma during lactation and secrete high levels of choline metabolites, namely phosphocholine (PCho) and glycerophosphocholine (GPCho). Our results demonstrate that the SKBr3 cell line (ER-) has a larger band area compared with the MCF-7 cell line (ER+) in all the lipids region. Although we do not have more evidences to correlate $\mathrm{C}-\mathrm{H}$ content and Pcho content, our hypothesis is that our results (higher $\mathrm{C}-\mathrm{H}$ content) can be explained by the fact that $\mathrm{SKBr} 3$ cells have increased ChoK expression and, consequently, greater generation of PCho [8].

Additionally, we looked for biomarker ratios that would enable us to discriminate between lesions and normal cells. We selected absorption bands that represent each macromolecule, as shown in Table 2. With respect to DNA, the absorption bands related to the $\mathrm{PO}_{2}$ symmetric stretching vibrational mode $\left(1084 \mathrm{~cm}^{-1}\right)$ were considered, because this bond is abundant in this macromolecule in the same way that $\mathrm{C}-\mathrm{N}$ and $\mathrm{C}-\mathrm{C}$ stretchings $\left(1120 \mathrm{~cm}^{-1}\right)$ are abudant in the RNA molecule. The bands which represent the protein region $\left(1650\right.$ and $\left.1540 \mathrm{~cm}^{-1}\right)$ are well applied in ratio analysis $[13,15,16]$. The lipids were represented by the sebum absorption band $\left(1740 \mathrm{~cm}^{-1}\right)$, because according to Movasaghi et al. [16], and Mantsch and Chapman [13], this band represents a lipid macromolecule well, without influence of the protein vibrational modes. Having defined the absorption bands, we calculated the ratio between their areas and the obtained indices that are shown in Figs 5 and 6.

The first calculated ratio corresponds to the protein region: amide I $\left(1650 \mathrm{~cm}^{-1}\right) /$ amide II $\left(1540 \mathrm{~cm}^{-1}\right)$. The index was $1.88 \pm 0.17$ for the SKBr3 cell line and $0.53 \pm 0.09$ for MCF-7 cells. This index allows for evaluation of the protein degradation level [26], since the amide absorptions are sensitive to protein conformation. In other words, an increase or decrease in this ratio could be attributed to changes in the composition of the whole protein pattern.

The ratio between proteins (in this case, the amide I absorption band area) and DNA can be related to malignant transformations; that is, this ratio increases as the tumor malignancy level rises [4]. The MCF-7 cell line had an index of around $0.35 \pm 0.03$, whereas SKBr3 had a higher value, $0.55 \pm 0.04$, which could indicate that $\mathrm{SKBr} 3$ cell line is derived from a more aggressive tumor compared with MCF-7. The ratio value considering the DNA and RNA absorption band are close $(2.26 \pm 0.12$ for $\mathrm{SKBr} 3$ cell line and $2.83 \pm 0.16$ for the MCF-7 cell line), which is not useful to distinguish between these cell lines. Finally, the index between amide I and lipids was $22.78 \pm 0.72$ for the SKBr3 cell line and $16.00 \pm 0.31$ for MCF-7 cells.

The bands presenting peak displacement were also considered here. The absorption bands with some significant peak displacement were $1120 \mathrm{~cm}^{-1}$ (related to RNA), $1651 \mathrm{~cm}^{-1}$ (amide I $\alpha$ helix structure), $2851 \mathrm{~cm}^{-1}$ (related to lipids $-\mathrm{CH}_{2}$ stretching) and $2962 \mathrm{~cm}^{-1}$ (related to lipids $-\mathrm{CH}_{3}$ stretching). The 


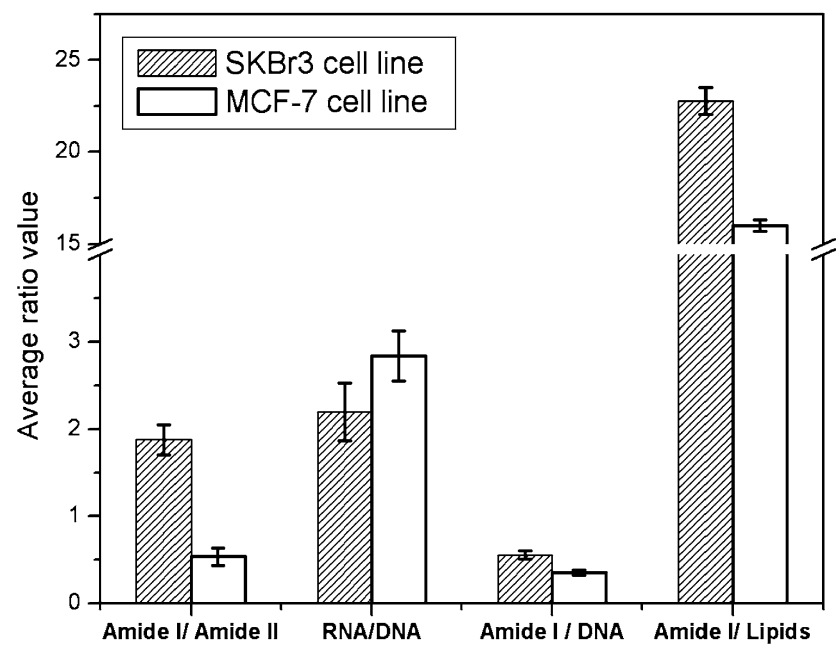

Fig. 5. Average ratio value of SKBr3 and MCF-7 cell lines that show statistical differences $(p<0.05)$, considering different absorption band areas: DNA $\left(1084 \mathrm{~cm}^{-1}\right)$, RNA $\left(1120 \mathrm{~cm}^{-1}\right)$, proteins $\left(1650 \mathrm{~cm}^{-1}\right.$ and $1540 \mathrm{~cm}^{-1}$, amide I and amide II bands, respectively) and lipids $\left(1740 \mathrm{~cm}^{-1}\right)$.

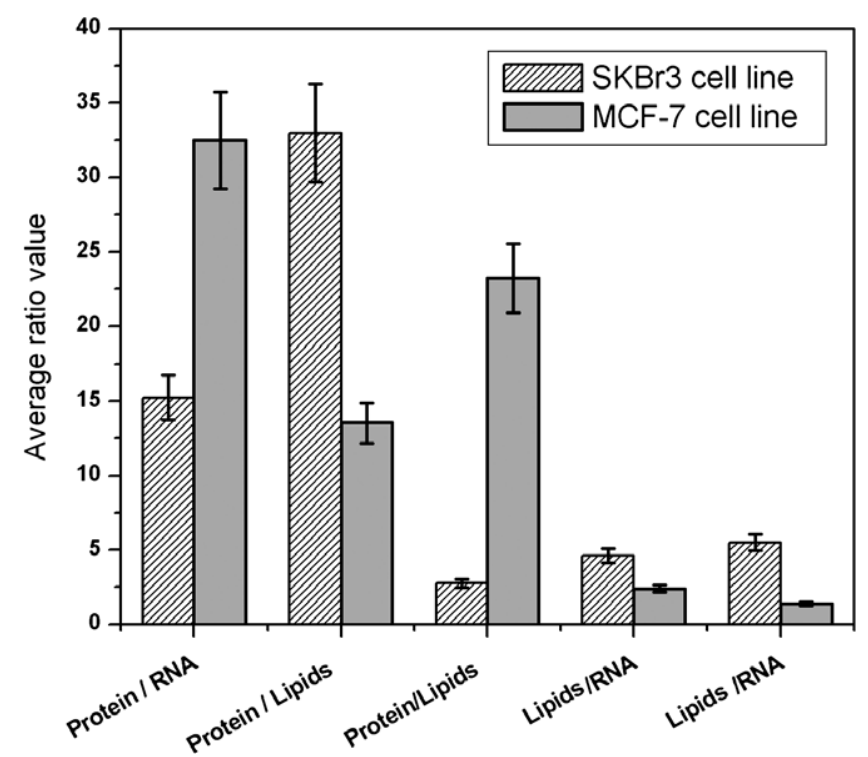

Fig. 6. Average ratio value of SKBr3 (breast cancer with negative estrogen receptor) and MCF-7 (breast cancer with positive estrogen receptor) cell lines considering other absorption band areas: $1120 \mathrm{~cm}^{-1}$ (RNA), $1651 \mathrm{~cm}^{-1}$ (protein), $2851 \mathrm{~cm}^{-1}$ (lipids) and $2962 \mathrm{~cm}^{-1}$ (lipids).

peak displacement can be assigned to changes in the environment in which the chemical bonds are immersed, causing changes in the vibrational frequencies. These bands could be employed to differentiate cell groups. Looking for the bands that show peak displacement, we selected more ratios and observed different ratio values for the two cell lines (see Fig. 6).

The first calculated ratio, referent to proteins and RNA, had an index value around $15.25 \pm 1.09$ for the SKBr3 cell line and $32.50 \pm 3.66$ for MCF-7 cells. The first ratio between proteins and lipids had 
an index around $32.97 \pm 2.29$ (SKBr3) and $13.54 \pm 1.09$ (MCF-7) considering the absorption band located at $2851 \mathrm{~cm}^{-1}$; the second ratio between proteins and lipids (considering the absorption band area located at $2962 \mathrm{~cm}^{-1}$ ) led to values around $2.77 \pm 0.30(\mathrm{SKBr} 3)$ and $23.21 \pm 1.87$ (MCF-7). Two more ratios relating both absorption band areas from lipids $\left(2851\right.$ and $\left.2962 \mathrm{~cm}^{-1}\right)$ and RNA $\left(1120 \mathrm{~cm}^{-1}\right)$ were calculated: the first ratio was $4.62 \pm 0.51$ (SKBr3) and $2.40 \pm 1.63$ (MCF-7), considering the lipids absorption band located at $2851 \mathrm{~cm}^{-1}$, and the second was $5.50 \pm 0.48(\mathrm{SKBr} 3)$ and $1.40 \pm 0.09$ (MCF-7), located at $2962 \mathrm{~cm}^{-1}$.

\section{Conclusions}

This work demonstrates that it is possible to distinguish between MCF-7 and SKBr3 cells through differences in their FTIR spectra. Although both cell lines are derived from the same type of breast cancer (both are adenocarcinomas from a mammary gland, derived from metastatic pleural effusion), this methodology enables distinction between two cell lines, where the main difference between them, is the expression or not of estrogen receptors. It was possible to observe statistical differences $(p<0.05)$ by analyzing the absorption band areas and peak shifts. The molecular mechanisms and changes therein, which lead to the development and progression of breast carcinoma, are extremely complex, so the significant differences observed between the two cells lines can lead to future work on the identification of different types of breast cancer.

\section{Acknowledgements}

This research was supported by Capes (Coordenação de Aperfeiçoamento de Pessoal de Nível Superior), CNPq (Conselho Nacional de Desenvolvimento Científico e Tecnológico) and FAPESP (Fundação de Amparo à Pesquisa do Estado de São Paulo).

\section{References}

[1] J. Ahmedin, R. Siegel, E. Ward, Y. Hao, J. Xu and T. Murray, Cancer statistics, Cancer J. Clin. 58 (2008), 71-96.

[2] D.C. Allred, The origins of oestrogen receptor negative breast cancer, Breast Cancer Res. 9 (2007), S20.

[3] P.G.L. Andrus and R.D. Strickland, Cancer grading by Fourier transform infrared spectroscopy, Biospectroscopy 4 (1998), 37-46.

[4] E. Benedetti, E. Bramanti, F. Papineschi and I. Rossi, Determination of the relative amount of nucleic acids and proteins in leukemic and normal lymphocytes by means of Fourier transform infrared microspectroscopy, Appl. Spec. 51 (1997), 792-797.

[5] L.P. Choo, M. Jackson, W.C. Halliday and H.H. Mantsch, Infrared spectroscopic characterization of multiple sclerosis plaques in the human central nervous system, Biochim. Biophys. Acta 1182 (1993), 333-337.

[6] G.M. Clark, Prognostic and predictive factors, in: Diseases of the Breast, Vol. 2, Lippincott Williams \& Wilkins, Philadelphia, PA, 2000, pp. 489-514.

[7] R. Clarke, R.B. Dickson and M.E. Lippman, Hormonal aspects of breast cancer, Crit. Rev. Oncol. Hematol. 12 (1992), $1-23$.

[8] G. Eliyahu, T. Kreizman and H. Degani, Phosphocholine as a biomarker of breast cancer: Molecular and biochemical studies, Int. J. Cancer 120 (2007), 1721-1730.

[9] R.M. Elledge and S.A.W. Fuqua, Estrogen and progesterone receptors, in: Diseases of the Breast, Vol. 2, Lippincott Williams \& Wilkins, Philadelphia, PA, 2000, pp. 471-488.

[10] H.H. Eysel, M. Jackson, A. Nikulin, R.L. Somorjai, G. Thomson and H.H. Mantsch, A novel diagnostic test for arthritis: Multivariate analysis of infrared spectra of synovial fluid, Biospectroscopy 3 (1997), 161-167. 
[11] P.R. Griffiths and J.A. de Haseth, Fourier Transform Infrared Spectrometry, Wiley, New York, 1986.

[12] K.Z. Liu, M.H. Shi and H.H. Mantsch, Molecular and chemical characterization of blood cells by infrared spectroscopy: a new optical tool in hematology, Blood Cells Mol. Dis. 35 (2005), 404-412.

[13] H. Mantsch and D. Chapman, Infrared of Spectroscopy of Biomolecules, 1st edn, Wiley-Liss, New York, 1996.

[14] A.R. Molina, R. Gutierrez, M.A. Ramos, J.M. Silva, J. Silva, F. Bonilla, J.J. Sanchez and J.C. Lacal, Increased choline kinase activity in human breast carcinomas: clinical evidence for a potential novel antitumor strategy, Oncog. 21 (2002), 4317-4322.

[15] L.B. Mostaço-Guidolin, L.S. Murakami, A. Nomizo and L. Bachmann, Fourier transform infrared spectroscopy of skin cancer cells and tissues, Appl. Spec. Rev. 44 (2009), 438-455.

[16] Z. Movasaghi, S. Rehman and I. Rehman, Fourier Transform Infrared (FTIR) spectroscopy of biological tissues, Appl. Spec. Rev. 43 (2008), 134-179.

[17] S. Neviliappan, L. Fang Kann, T. Tiang Lee Walter, S. Arulkumaran and P.T.T. Wong, Infrared spectral features of exfoliated cervical cells, cervical adenocarcinoma tissue, and an adenocarcinoma cell line (SiSo), Gynecol. Oncol. 85 (2002), $170-174$.

[18] H. Peng, H.K. Kinyamu, L. Wang, J. Martin, T.K. Archer and C. Teng, Estrogen induces estrogen-related receptor-gene expression and chromatin structural changes in Estrogen Receptor (ER)-positive and ER-negative breast cancer cells, J. Biol. Chem. 283 (2008), 6752-6763.

[19] R.E. Pollock, D.W. Kufe, R.C. Bast, W.N. Hait, R.R. Weichselbaum, J.F. Holland, E. Frei and W.K. Hong (eds), Cancer Medicine, 5th edn, BC Decker, Hamilton, 2000.

[20] B. Rigas, S. Morgello, I.S. Goldman and P.T. Wong, Human colorectal cancers display abnormal Fourier-transform infrared spectra, Proc. Natl. Acad. Sci. USA 87 (1990), 8140-8144.

[21] J.A. Rillema, Hormone regulation of choline uptake and incorporation in mouse mammary gland explants, Exp. Biol. Med. 229 (2004), 323-326.

[22] E.M. Rohlfs, S.C. Garner, M.H. Mar and S.H. Zeisel, Glycerophosphocholine and phosphocholine are the major choline metabolites in rat milk, J. Nutr. 123 (1993), 1762-1768.

[23] M. Romeo, B. Mohlenhoff and M. Diem, Infrared micro-spectroscopy of human cells: causes for the spectral variance of oral mucosa (buccal) cells, Vib. Spectrosc. 42 (2006), 9-14.

[24] C.P. Schultz, K.Z. Liu, J.B. Johnston and H.H. Mantsch, Study of chronic lymphocytic leukemia cells by FT-IR spectroscopy and cluster analysis, Leukemia Res. 20 (1996), 649-655.

[25] C.P. Schultz, K.Z. Liu, P.D. Kerr and H.H. Mantsch, In situ infrared histopathology of keratinization in human oral/oropharyngeal squamous cell carcinoma, Oncol. Res. 10 (1998), 277-286.

[26] L. Vickery, T. Nozawa and K. Sauer, Determination of the secondary structure content of proteins in aqueous solutions from their amide I and amide II infrared bands. Comparison between classical and partial least-squares methods, Biochemistry 29 (1990), 8771-8779.

[27] P.T.T. Wong, R.K. Wong, T.A. Caputo, T.A. Godwin and B. Rigas, Infrared spectroscopy of exfoliated human cervical cells: evidence of extensive structural changes during carcinogenesis, Proc. Natl. Acad. Sci. USA 88 (1991), 10988-10992.

[28] B.R. Wood, L. Chiriboga, H. Yee, M.A. Quinn, D. McNaughton and M. Diem, Fourier transform infrared (FTIR) spectral mapping of the cervical transformation zone, and dysplastic squamous epithelium, Gynecol. Oncol. 93 (2004), 59-68.

[29] B.R. Wood, M.A. Quinn, B. Tait, M. Ashdown, T. Hislop, M. Romeo and D. McNaughton, FTIR microspectroscopic study of cell types and potential confounding variables in screening for cervical malignancies, Biospectroscopy 4(2) (1998), 75-91. 


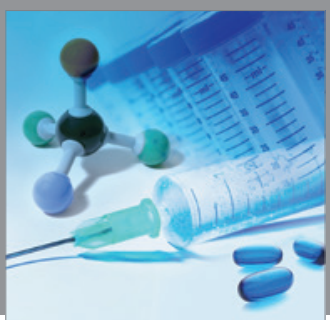

International Journal of

Medicinal Chemistry

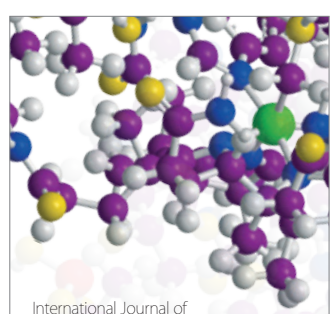

Carbohydrate Chemistry

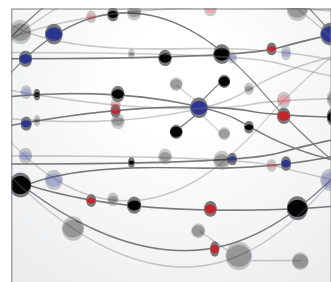

The Scientific World Journal
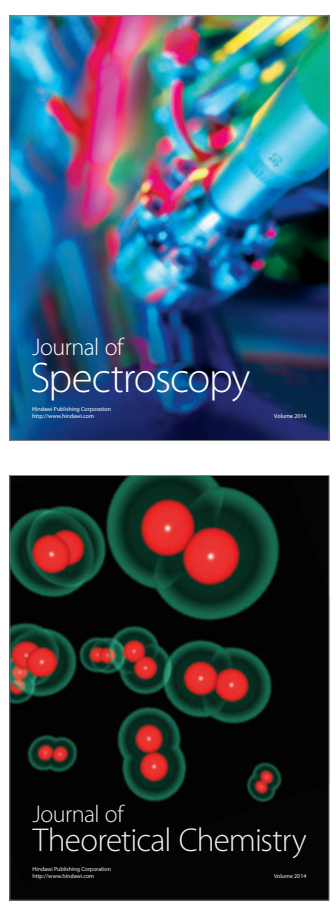
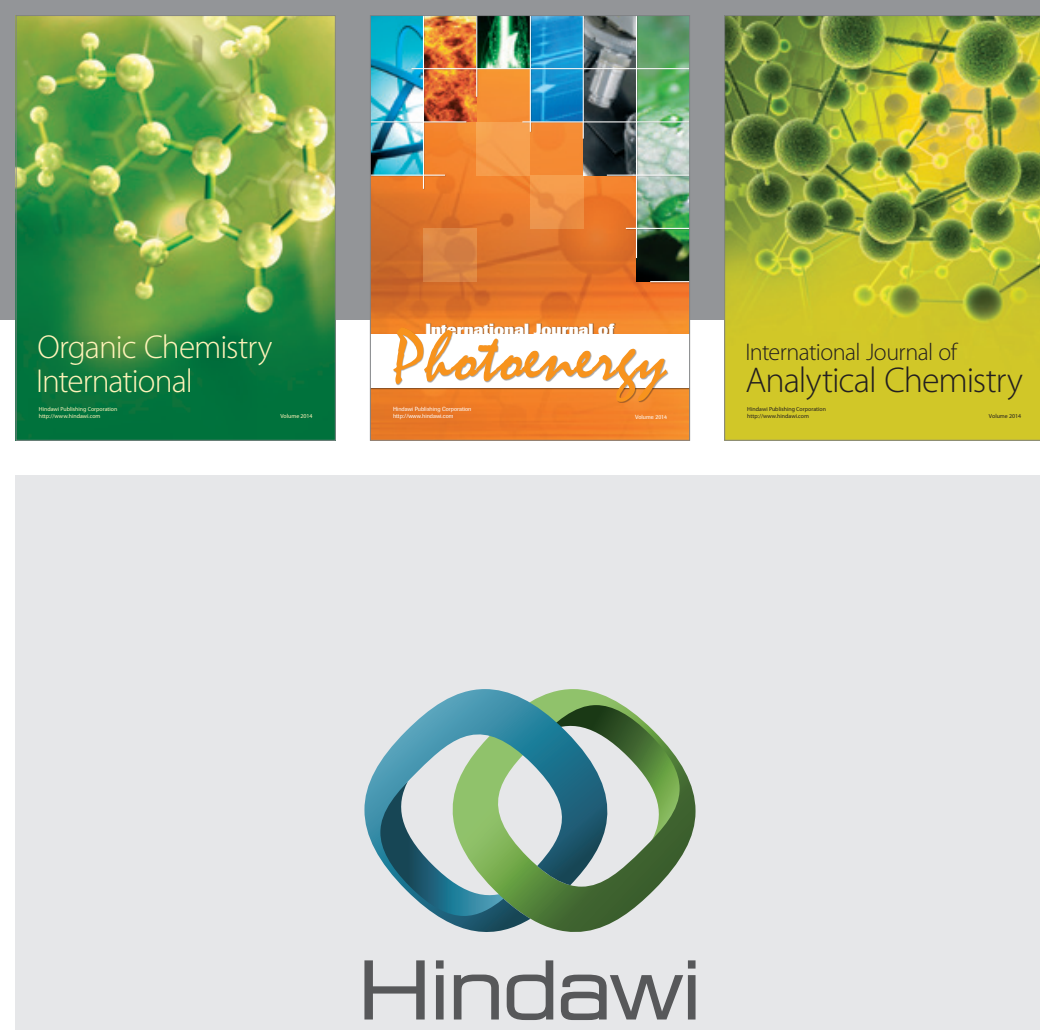

Submit your manuscripts at

http://www.hindawi.com
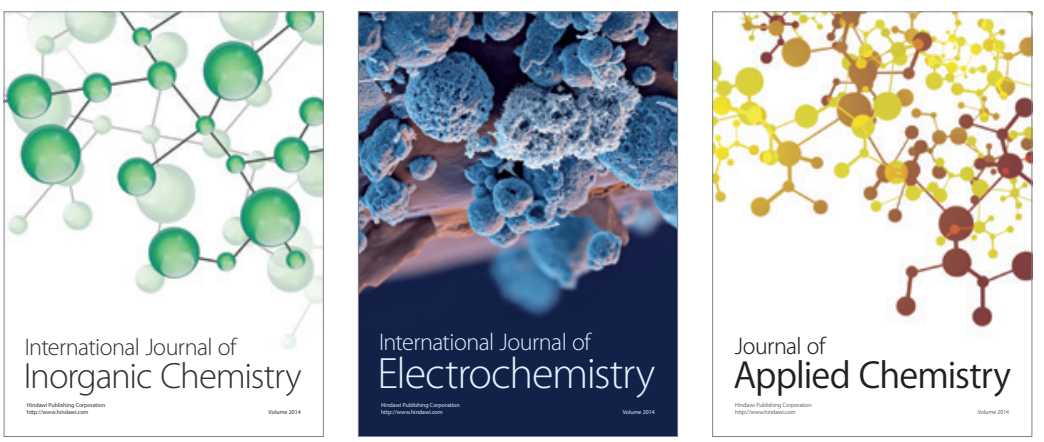

Journal of

Applied Chemistry
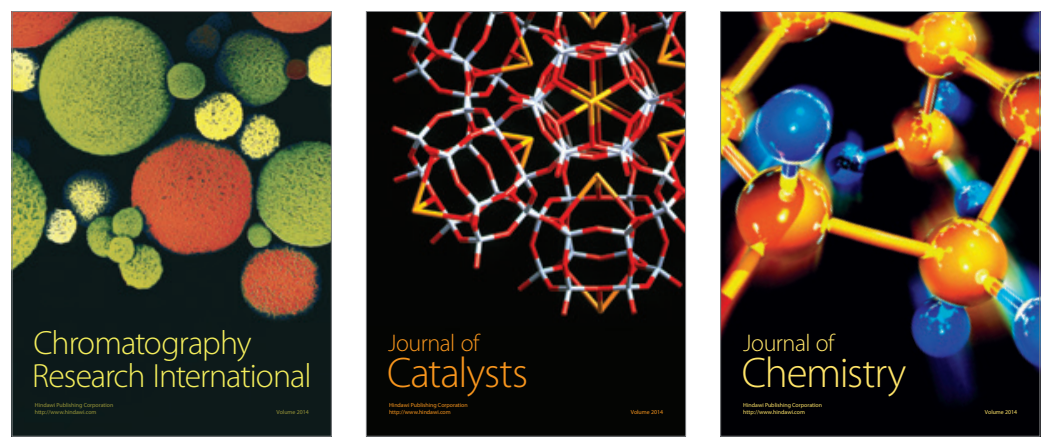
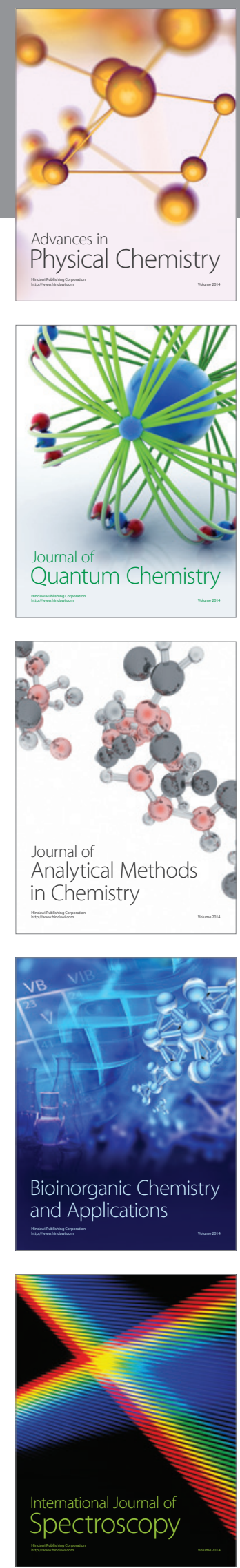